\title{
Envelhecimento e Educação para Resiliência no Idoso
}

\author{
Carolina Silva Sousa' \\ Francisco P. Rodríguez-Miranda" \\ 'Universidade do Algarve - Portugal \\ "Universidade de Extremadura - Espanha
}

RESUMO - Envelhecimento e Educação para Resiliência no Idoso. A escolha da temática envelhecimento e educação para resiliência prende-se como uma questão crucial no atual contexto da preparação e educação do adulto e que visa preparar o ser humano para enfrentar, na sua velhice, uma vida participativa bem sucedida em todos os contextos relacionais. O design/ encenação metodológico é feito a partir de ferramentas conceptuais em torno da interface entre a velhice e a educação para a resiliência do idoso, a qual se pode apresentar como uma importante área do conhecimento que possibilita implementar e consolidar capacidades intrínsecas ao sujeito que poderão contribuir para a superação de dificuldades inerentes ao ato educativo, pontuado pelo irrepetível e pelo imprevisível.

Palavras-chave: Educação. Envelhecimento. Resiliência Educacional.

ABSTRACT - Educational for Resilience in Ageing. The choice of the topic ageing and educational resilience is a very important issue in the present context of adult training and education, aimed at preparing human beings to face, as they age, a successful active life in all relational contexts. The methodological design is based on conceptual tools, within the interface between aging and education resilience of the elderly. It can be presented as an important area of knowledge that enables the implementation and strengthening of capabilities that may contribute to overcome the difficulties inherent to the educational act, marked by the unpredictable and unrepeatable.

Keywords: Education. Ageing. Educational Resilience.

Educação \& Realidade, Porto Alegre, v. 40, n. 1, p. 33-51, jan./mar. 2015. 
Envelhecimento e Educação para Resiliência no Idoso

\section{Introdução}

Apresentando-se o ato de educar, hoje, como um enorme desafio que não se torna possível através de uma mera transmissão de técnicas ou de saberes científicos e pedagógicos, não é por demais realçar a importância da Educação enquadrada no paradigma de aprendizagem da formação ao longo da vida - já que este se pode apresentar como algo que poderá constituir para os sujeitos por exemplo, os idosos, satisfação de necessidades de enriquecimento pessoal e de convivência e participação social, podendo assumir estes melhores e mais congruentemente o seu próprio desenvolvimento, com qualidade de vida, beneficiando a sociedade com a sua experiência. Até porque para desenvolver um país é indispensável investir nos seus recursos humanos. E isto porque o nível de vida e o desenvolvimento de um país está cada vez mais dependente da qualidade da educação que se pratica nesse país. Do nosso ponto de vista, só um desenvolvimento centrado no ser humano e uma sociedade de participação baseada no pleno respeito pelos direitos humanos pode conduzir a um desenvolvimento sustentável e equitativo. Por outro lado, a conceptualização sobre a educação aponta, ainda, que a integração social, por exemplo, do idoso, é uma das vias para lhes maximizar a autoconfiança, a maturidade, a competência, o bem estar físico, emocional e social, a resiliência e contribuir, de forma positiva, para um envelhecimento com uma vida participativa bem sucedida em todos os contextos relacionais.

Todavia, todos estão conscientes, quer em Portugal, quer no Brasil, que a gestão das políticas sociais está ancorada em parcerias entre estado, sociedade civil e iniciativa privada e num valor social - solidariedade. E as opções políticas requerem a arte de contemplar as exigências das minorias ou problemáticas mais em foco, esperando-se dos programas do governo mais eficiência nos gastos e mais eficácia e efetividade nos resultados, sobretudo quando falamos de educação, envelhecimento e educação para a resiliência.

\section{Educação e Profissionalidade}

Estamos convictos de que na atualidade, o desenvolvimento profissional no campo educativo é pontuado por um acervo de fatores potenciadores de crise na educação e formação - e isto em termos mundiais - de natureza exógena relativamente aos sujeitos que a protagonizam. Trata-se de mudanças em nível social, quer seja do domínio da investigação científica e tecnológica ou nas repercussões dos seus resultados nos sistemas organizacionais da vida em sociedade e consequentemente, na esfera pessoal dos indivíduos por eles abrangidos. Importa, então, equacionar o seguinte: será que não existem fatores cuja origem de natureza endógena, intrapessoal e, que na relação dialética entre os domínios do endo e da exogenia, não poderão contribuir quer para agudizar a discrepância, nuns casos, quer para relevá-la noutros? 
A este propósito gostaria de referir que contrariamente a este clima negativista, nós falamos do prazer de educar, afirmando que a gênese desse prazer é o encontro entre um projeto para os educandos, proposto pelo educador que acredita, ainda que pouco, na sua profissão e um público disponível para aceitar esse projeto. Parece, pois ser de admitir a possibilidade de o próprio profissional intervir voluntariamente no jogo das suas circunstâncias, ou seja, refletir criticamente sobre a multivariância dos dados do seu problema, reforçando o seu desempenho profissional e o devir pessoal, através do reconhecimento da sua capacidade de pensar, ter opinião, tomar decisões, desenvolver projetos de ação consequentes, solidários e inovadores e de reformulá-los ou pôr em causa, sempre que isso legitimamente se justifique. Tal fato leva-nos a colocar outra questão: Até que ponto, estes indicadores poderão estar diretamente ligados à forma como o educador cuida de si mesmo, no sentido da sua implicação na construção da produção de sentido no seu projeto de vida e no dos seus educandos, por exemplo, o seu aluno idoso?

Tomando por pano de fundo a nossa experiência em programas de doutoramento, designadamente na Universidade de Huelva e na Universidade de Granada, Espanha, a nossa experiência nos cursos de pós-graduação na Universidade do Algarve, Portugal, bem como a nossa participação no Programa Erasmus em várias universidades públicas da Europa, é nossa convicção que o próprio profissional deve pugnar por um desempenho profissional e um devir pessoal de elevada competência, em consonância com a sua própria convicção de que construindo sentido para a sua existência, terá maiores oportunidades de realização bem sucedida, desdobrando-se num projeto de vida pessoal e profissional, pautado pela construção de valores atitudinais, criativos e vivenciais.

E não será por demais afirmar que a profissionalidade docente que as atuais condições exigem - passará pela capacidade do educador assumir uma perspectiva crítica que, trabalhando com o novo conhecimento - caracterizado por uma natureza cultural, social e contextual -, lhe possibilite enfrentar com sabedoria os problemas complexos, tomar decisões oportunas e adequadas e implementar soluções socialmente negociadas que possam transformar positivamente as realidades de cada contexto, num quadro de flexibilidade cognitiva e metacognitiva e de ação, capacidades sem as quais nenhuma reconstrução de conhecimento é possível. Neste enquadramento, justifica-se afirmar, que na atualidade são especialmente evidentes, entre outros, as dialéticas entre a intra e a intersubjetividade, entre a subjetividade e a objetividade, entre o eu e o outro, entre a cognição e a ação, entre a formação e a investigação, entre o pessoal e o individual, e, entre a teoria e a prática e também a problemática das transações ecológicas que, tal como Bronfenbrenner (1979) refere, intercontextualizam as situações educativas. Trata-se de um movimento que emerge em vários quadrantes da investigação e não apenas na que se relaciona com a formação docen-

Educação \& Realidade, Porto Alegre, v. 40, n. 1, p. 33-51, jan./mar. 2015. 35

Disponível em: <http://www.ufrgs.br/edu_realidade> 
te, e opõe-se frontalmente aos pressupostos fundamentadores das várias manifestações do paradigma tecnicista e instrumental, próprio do pensamento positivista e cartesiano. Efetivamente, onde no passado se instalavam certezas, instalam-se agora dúvidas, onde era comum apresentar-se ruturas e descontinuidades artificialmente concebidas, agora se apresentam hipóteses explicativas de coerência mais holística, pois no passado acreditava-se no poder explicativo do facto, hoje se coloca o relativismo da sua representação e do sentido cultural que a estabelece para o outro.

E ao desmoronar dos mitos não corresponde, mais, como seria pensável, uma generalizada descrença no homem, porque por sobre essa desconstrução e por sobre as suas inconsistências tornadas explícitas, se inicia já um forte movimento de construção de sentidos social e contextualmente mais legítimos, emergindo como indicadores de um tempo ainda algo novo, mas muito promissor. Neste contexto, assume um papel de relevo o desenvolvimento de vetores que se prendem com (i) a necessidade do educador de adultos se tornar agente e produzir teoria a partir das práticas que desenvolve; (ii) a necessidade do educador de adultos conhecer as situações e os problemas que originam os conhecimentos para os resignificar em contexto e na contemporaneidade; e, (iii) a necessidade do educador de adultos equacionar os problemas, tendo em vista o desejo e significado dos conhecimentos a serem apreendidos.

E nunca é por demais revisitar parâmetros essenciais à evolução da cognição que nos caracteriza, quer seja em Portugal, quer seja no Brasil, em contraponto àquele movimento que pretendeu ignorar o papel determinante das dimensões ecológica, social, pessoal e cultural na construção de um conhecimento que facilite a compreensão da realidade nas vertentes da complexidade, incerteza, e ambiguidade que caracterizam o ato educativo, sobretudo quando pensamos na educação e formação de adultos resilientes. Um educador de adultos não pode desligar-se da sua proposta de implementar com os seus educandos um processo pedagógico transformador, assumindo naturezas de múltiplas ordem, desde a pragmática, à objetiva, práxica, argumentativa, cultural, relativa, prospetiva, instável, dinâmica e valorativa, configurando-se esta como uma matriz fundacional que sustenta um processo pedagógico transformador a implementar para ser reconstruído, através de novas e múltiplas fontes e de novas estratégias, ou seja, um projeto que implica, afinal, uma outra forma de estar, uma outra coerência epistémica que legitima e repõe a competência e a dignidade do educador.

Todavia, há que sublinhar ainda que a conceptualização sobre a educação, hoje, prende-se, também, com educar em contexto de diversidade, o que se torna uma necessidade e um imperativo na educação que concebemos orientada para o sucesso, no caso concreto, do idoso. A educação para a diversidade deverá reger-se por princípios que devem 
envolver as pedagogias cooperativas, a implicação de todos na tomada de decisões, o desenvolvimento e a elaboração de projetos de trabalho e a importância dos interesses da comunidade acadêmica. A cultura da diversidade consiste afinal no incremento dela mesma em toda a cultura da instituição educativa. Ultrapassa a questão das adaptações curriculares, implica a procura de outro modelo, de outro sistema educativo e de outro currículo que conheça, que compreenda e respeite a diversidade. A instituição educativa da diversidade tem que ser uma instituição educativa que aprenda estratégias para a resolução de problemas da vida quotidiana de forma cooperativa e solidária (López, 1990).

Por conseguinte, a formação docente - que nunca está concluída - pode ser entendida como um processo evolutivo que prossegue ao longo de todo o ciclo de vida e que constitui, antes de mais, um caso particular do desenvolvimento humano, em que aposta educativa deverá primar pela melhoria da qualidade da intervenção profissional e pela promoção da investigação nesta área científica, procurando responder a preocupações político-educativas relativamente a prioridades socioculturais, educativas e econômicas, centradas em processos de inovação na educação seja formal, não formal e/ou informal, em que a educação para a resiliência do idoso se pode apresentar como uma importante área do conhecimento que possibilita implementar e consolidar capacidades intrínsecas ao sujeito que poderão contribuir para a superação de dificuldades inerentes ao ato educativo, pontuado pelo irrepetível e pelo imprevisível.

E estando ligada aos cursos de mestrado e doutoramento, quer em Educação quer em Gerontologia Social, nas universidades onde trabalhamos, merece-nos uma atenção muito especial o ciclo de vida do ser humano, como é o envelhecimento, assunto do próximo tópico.

\section{Desenvolvimento Humano e Envelhecimento}

E iniciamos este tópico com as seguintes questões: Até que ponto as várias experiências derivadas da vivência do envelhecimento das populações não originaram novas formulações baseadas na possibilidade de uma boa e saudável velhice, e que se prendem com os fatores que influenciam o desenvolvimento humano, tais como, entre outros, a hereditariedade e o meio? Como equacionar o papel da contribuição das investigações no âmbito da biologia, da medicina, e das ciências do comportamento e das ciências sociais, enquanto matriz configuradora de uma nova gerontologia social, já tão longe daquela gerontologia social inicial para quem a velhice era entendida como um problema a resolver?

O desenvolvimento humano é o processo através do qual a pessoa adquire uma concepção mais ampliada, diferenciada e válida do ambiente ecológico e se torna mais motivada e mais apta a envolver-se em atividades que, em níveis de complexidade semelhante ou superior, 
na forma e no conteúdo, evidenciam as propriedades do ambiente, as sustentam ou as reestruturam. Para nós (Sousa, 2003) o desenvolvimento humano é algo que resulta de uma interação dinâmica, que ocorre ao longo de todo o ciclo de vida, entre um indivíduo em desenvolvimento e um contexto em permanente transformação; uma relação entre as características idiossincráticas e as características do meio; entre as características psicológicas do sujeito e as condicionantes situacionais. Pode-se, assim, defender que as mudanças verificadas no comportamento humano, ao longo da vida, têm origem tanto em fatores que compõem uma matriz de natureza biológica, psicológica, social e evolutiva, como em contingências temporais vividas pelos seres humanos no decurso das próprias vidas.

São várias as teorias que procuram explicar o desenvolvimento humano, dando origem a quadros conceptuais distintos, mas com bastantes semelhanças entre si. Lasuíta (1989) faz uma comparação dos mesmos e evidencia o seguinte conjunto de aspectos caracterizadores: a multidimensionalidade, a multidirecionalidade e a descontinuidade, que se apresentam como os principais aspetos do desenvolvimento humano, que pressupõe na vida adulta, gradativamente, uma maior variabilidade do comportamento individual e várias mudanças de vida; a complexidade das mudanças de comportamento que podem ocorrer no decurso do ciclo de vida, que deve ser perspectivada em termos de multicausalidade, sendo três os sistemas de influência: o ontogenético, em função da idade; o evolutivo, em função da história de vida; e o não normativo, em função das condições ambientais e biológicas ligadas às experiências idiossincráticas. Neste enquadramento, podemos defender que o conceito atual de desenvolvimento humano deverá ser entendido numa perspectiva multidisciplinar e transdisciplinar, que compreende, e onde se consubstanciam interativamente, as dimensões psicológica, social, comunitária, econômica, cultural, científico-técnica e educacional.

O desenvolvimento humano constrói-se, pois, não apenas por mudanças ou transições, ao longo da vida, determinadas tanto por fatores de natureza maturacional de caráter pessoal, como por fatores resultantes da interação entre as características pessoais e a estimulação do meio, mas também como resultado do modo como em cada indivíduo se repercutem essas mudanças e transições e da reestruturação que, em função delas, nele se opera, como ocorre no envelhecimento, assunto do próximo tópico.

\section{Envelhecimento Humano}

Segundo Paúl e Fonseca $(2001 ; 2005)$, na próxima década, um em cada cinco portugueses terá mais de 65 anos e isto terá implicações inevitáveis na nossa sociedade. Portugal, de acordo com os Censos de 2011 do Instituto Nacional de Estatística (INE), apresenta um quadro de 
envelhecimento demográfico bastante acentuado, com uma população idosa (pessoas com 65 e mais anos de idade) de 19,15\%, uma população jovem (pessoas com 14 e menos anos) de 14,89\% e uma esperança média de vida à nascença de 79,2 anos. De referir que neste ano de 2011, a população residente em Portugal foi estimada em 10.562.178, dos quais $19 \%$ eram idosos (2.010.064 pessoas idosas) (PORDATA, 2012). Por outro lado, dados publicados pela United Nations (2001) no Word Population Ageing, 1950-2050, apontam, ainda, para a existência, em Portugal, de 300 pessoas com 100 ou mais anos, prevendo-se que em 2025 esse número ascenda aos $1.800 \mathrm{e}$, em 2050, atinja 6.400 pessoas.

Assim, é importante neste fenômeno globalizante saber definir e diferenciar, o envelhecimento como processo, a velhice enquanto fase da vida e o velho ou idoso como resultado final, pois constituem um conjunto, cujos componentes estão intimamente relacionados (Freitas; Py; Neri; Cançado; Doll; Gorzoni, 2006). Por outro lado, são três os conceitos de que nos podemos socorrer para definir a velhice, concretamente: (i) o da idade cronológica, que corresponde à idade oficial, com base na identificação; (ii) o da idade biológica que corresponde ao estado orgânico e funcional dos diferentes órgãos, aparelhos e sistemas, e, (iii), por último, o da idade psicológica, que pode não depender da idade nem do estado orgânico.

No racional teórico de Paúl e Fonseca (2001), envelhecer tem sido associado à ocorrência de várias patologias crônicas que influenciam o modo de viver e o processo de envelhecimento, predispondo a uma maior vulnerabilidade e fragilidade e, consequentemente, a um comprometimento da qualidade de vida $(\mathrm{QV})$, o que nos remete para a incursão científica em termos de um entendimento sobre envelhecimento bem sucedido versus envelhecimento ativo.

\section{Modelo de Envelhecimento Bem Sucedido}

Para Teixeira e Neri (2008) trata-se de um construto que levanta algumas discordâncias entre os investigadores. Ainda assim Fried, Freedman, Endres e Wasik (1997), Lupien e Wan (2004), Phelan e Larson (2002), Ramos (2003), Rowe e Kahn (1997), apontam que em nível social o envelhecimento bem-sucedido constitui-se como um processo evolutivo, produtivo e saudável. Em seu entender, o idoso deverá adaptar-se às mudanças implícitas ao normal envelhecimento do organismo (quer ao nível biológico, quer ao nível psicológico), encontrando soluções para as suas condições de vida associadas a estas mudanças. Este facto é reforçado pelo Modelo de Envelhecimento Bem-Sucedido preconizado por Baltes (1987; 1997), e explorado a partir de três eixos implícitos à sua conceptualização, concretamente: (i) balanço entre ganhos e perdas de caráter desenvolvimentista; (ii) recurso ao Modelo de Otimização Seletiva com Compensação (SOC) como explicação básica do processo adaptativo inerente à capacidade de envelhecer com êxito; e, (iii) modi-

Educação \& Realidade, Porto Alegre, v. 40, n. 1, p. 33-51, jan./mar. 2015.

Disponível em: <http://www.ufrgs.br/edu_realidade> 
ficação nas modalidades de regulação da identidade pessoal (Fonseca, 2005). Baltes e Baltes (1990) enunciaram um padrão de estratégias para favorecer um envelhecimento bem-sucedido, onde se destaca a preservação de um estilo de vida saudável que promove a redução da probabilidade de ocorrência de condições patológicas, muitas vezes, decorrentes do próprio envelhecimento. Este constructo influi na manutenção de uma visão otimista da vida, sendo a mesma uma forma efetiva de compensar as perdas que vão ocorrendo, acentuando positivamente o que ainda subsiste. Assim, o envelhecimento bem-sucedido induz a implementação de estilos de vida apropriados à idade, dados os limites de flexibilidade adaptativa (plasticidade), sendo que, em consonância com este propósito, os idosos devem procurar escolher e/ou criar ambientes amigáveis para subsistirem e se manterem ativos na sociedade atual (Fonseca, 2005).

É ainda de salientar diversos estudos (Baltes, 1997; Freund; Baltes, 1998), demonstrativos de que a população mais envelhecida recorre de forma intencional e concertada a estratégias de seleção-otimização- compensação, de tal modo que, apresenta níveis mais elevados nos indicadores subjetivos de envelhecimento bem-sucedido. Assim, o idoso seleciona objetivos pessoais nos quais deseja continuar a envolver-se, seja em função das metas que fixou para a sua vida, ou até mesmo, mediante as suas capacidades e motivações ou exigências que o ambiente lhe coloca.

Nesses objetivos pessoais selecionados, o idoso procura otimizar as suas capacidades, colocando em ação as mais importantes, sob o ponto de vista adaptativo, permitindo, manter a congruência entre os seus objetivos, interesses e desejos, bem como as suas relações sociais e concretas que realiza (Baltes 1997; Freund; Baltes, 1998). Segundo Baltes (1997) trata-se de um modelo multidimensional em que se retoma a ideia central inerente ao paradigma contextualista, ou seja, os indivíduos modelam e são agentes ativos do seu próprio desenvolvimento através de uma seleção de objetivos pessoais, da otimização do seu funcionamento individual na realização dos objetivos pessoais antecipadamente selecionados e, da compensação de perdas desenvolvimentistas por recurso a mecanismos compensatórios internos ou externos.

Ainda no que concerne ao envelhecimento bem-sucedido, é importante refletirmos sobre as diferentes áreas de intervenção desta conceptualização, em que se destacam, entre outras, a promoção da saúde fomentada pela implementação de programas integrativos de várias atividades físicas e atividades de intervenção psicológica direcionadas para os idosos, bem como pela prevenção da sua dependência face aos seus cuidadores formais e informais.

Por último, é de referir o entendimento de Fernández-Ballesteros (2002), segundo o qual o modelo multidimensional do Envelhecimento Bem-Sucedido preconiza uma baixa probabilidade de doença e defi- 
ciência associada, um elevado funcionamento cognitivo e físico e um grande envolvimento ativo com a vida.

\section{Modelo de Envelhecimento Ativo}

É cerca de 2000 que emerge com a Organização Mundial de Saúde uma nova conceptualização de envelhecimento, o envelhecimento ati$v o$, como um conceito inovador, reflexivo da importância que as perspectivas psicológicas de natureza contextualista têm vindo a adquirir, quer ao nível da compreensão dos mecanismos de adaptação face ao envelhecimento, quer na formulação de intervenções promotoras dessa mesma adaptação. O objetivo do envelhecimento ativo é aumentar a expectativa de uma vida saudável e, consequentemente, a qualidade de vida para todos os indivíduos que vão envelhecendo, não descurando os mais vulneráveis, fisicamente incapacitados e que requerem cuidados.

O tema do envelhecimento ativo tem ocupado um dos lugares cimeiros nas agendas mundiais, nomeadamente da Organização Mundial de Saúde, do Banco Mundial e da Comissão Europeia. Têm, também, vindo a ser proferidas diversas estratégias políticas e desenvolvidas medidas de intervenção social que procuram traduzir uma nova imagem da velhice e suscitar outras leituras e práticas sobre a realidade. O envelhecimento populacional e o aumento do peso socioeconômico e político dos mais velhos, à escala mundial, têm impulsionado fortes debates e resoluções sobre a sustentabilidade financeira dos Estados sociais e sobre a necessidade de garantir a coesão social.

Neste enquadramento, a Organização Mundial de Saúde (OMS, 2005) tem vindo a propor um entendimento sobre o envelhecimento ativo que integre as várias dimensões da vida pessoal e social e que contrarie a tendência para uma visão redutora, direcionada unicamente para a vertente da empregabilidade. Nesta perspectiva, por envelhecimento ativo entende-se como "[...] o processo de otimização das oportunidades de saúde, participação e segurança, com o fim de melhorar a qualidade de vida à medida que as pessoas envelhecem" (OMS, 2005, p. 13). Esta proposta da OMS sugere a promoção da participação dos idosos nos mais diversos domínios da vida pessoal e social, ao mesmo tempo que aponta para a necessidades de se respeitar as preferências e capacidades de cada um, nomeadamente na sua vontade de não participar, se for o caso.

E uma questão, neste momento, gostaríamos de colocar: Que fatores afinal poderão contribuir para o delineamento de um perfil de idoso resiliente? Como ajudar um idoso a enfrentar uma vida participativa bem sucedida em todos os contextos relacionais? E o que entender por resiliência na educação?

Educação \& Realidade, Porto Alegre, v. 40, n. 1, p. 33-51, jan./mar. 2015. 


\section{Educação para a Resiliência}

É a possibilidade de desenvolver capacidades necessárias para se sobrepuser às adversidades quotidianas, superando-as e transformando-se, com diferentes níveis de construção de uma vida pessoal e profissional significativa, saudável e construtiva. Podemos pensá-la como uma noção que pretende consubstanciar conceptualmente uma especificidade estrutural do desenvolvimento humano, que se traduzem na capacidade que denotam certas pessoas, grupos ou comunidades para fazer face ou mesmo ultrapassar os efeitos desestruturantes que seriam muito prováveis em consequência da exposição a certas experiências.

Todavia, uma vez que o desenvolvimento conceptual pode ser definido em termos da crescente adaptabilidade à mudança no confronto do sujeito com o meio e que a educação se propõe preparar os indivíduos a adequarem-se a um mundo em permanente mutação - que evoluirá de modo imprevisível - a intervenção educativa para a promoção da resiliência torna-se um lugar privilegiado não só de ativação conceptual no sentido do raciocínio abstrato, mas também de interação e de construção das orientações interpessoais, não só enquanto facilitadoras do processo de desenvolvimento, ensino e aprendizagem, mas também como fatores essenciais da construção da interpessoalidade, dimensão emergente da maior relevância que se tem vindo a destacar, assumindo uma importância específica, tornada atualmente essencial, constituindo um aspeto potencialmente motivador e insubstituível e contribuindo não só para ser facilitadora do processo educativo, mas também para introduzir novas intencionalidades educativas ligadas com a construção da pessoalidade do aluno, complementarmente aos objetivos tradicionalmente propostos pela educação.

Até porque nunca é demais lembrar quão essencial é, na formação e educação de pessoas adultas, incentivar os formandos a que desbloqueiem eventuais problemas com que se vão confrontando, dado que de tal depende, em larga medida, a qualidade e a adequação das relações interpessoais que, ao longo da vida, ele vai conseguir estabelecer com os outros.

\section{Resiliência: conceito e conceitos associados}

O desenvolvimento humano efetua-se num reequilíbrio permanente entre estabilidade e mudança, complexifica-se, ainda, dado o caráter qualitativo que pode ser atribuído a muitas dessas transformações, ao associar as diferenças individuais com a explicação ou a previsão das trajetórias desenvolvimentais que são características dos indivíduos ou dos grupos.

A problemática referenciada enquadra, assim, a noção de resiliência, noção atualmente fundamental em Educação, Psicologia e Saúde até porque os novos quadros conceptuais, que atualmente se esboçam 
evocando este conceito, atribuem-lhe um certo caráter diferencial sem deixarem, todavia, de formular expectativas que evidenciam o seu caráter evolutivo (Sousa, 2006).

A resiliência conteria uma componente diferencial, que explicaria a razão porque certos indivíduos, em circunstâncias aparentemente idênticas, lidam com a adversidade de um modo mais adequado do que outros. Seria, também, suscetível de evoluir, podendo, por isso ser ativada mediante certas intervenções apropriadas, nomeadamente em contextos educativos (Grotberg, 1995; 1997; 1999; Manciaux, 2003; Sousa, 2006). Neste sentido, a resiliência pode ser ensinada, adquirida através da educação. Aliás, não existiria vida humana, se os antepassados não tivessem ultrapassado riscos e vulnerabilidades em determinados períodos de vida, desenvolvendo para isso, proteção e capacidade de resiliência. Até porque a melhor preparação para a dificuldade é a própria dificuldade. Trata-se de um constructo que constituiria, no essencial, o principal fator responsável por preservar a estabilidade da estrutura psicológica do sujeito, no decurso da mudança e da complexificação progressiva que invariavelmente caracterizam o percurso do desenvolvimento psicológico ao longo da vida (Ohio State University, 2002), e cujos elementos estruturantes são os seguintes: adaptação fisiológica, adaptação e habituação psicológica, sentido de autoeficácia, capacidade de autorregulação comportamental e capacidade de reinterpretar experiências negativas ou de usá-las como aprendizagens positivas, podendo alguns idosos revelar-se mais autônomos, com índices explícitos de autoestima e uma orientação social positiva.

Todavia, há que referir, que apesar de todo o esforço investigativo que tem sido desenvolvido nos últimos anos em torno deste conceito, ainda não foi possível estabelecer com rigor e precisão, as circunstâncias em que a resiliência surge e se modifica durante a vida de cada um dos indivíduos.

E alguma questão poderá neste momento equacionar: Será que graça a os contributos da investigação em educação e resiliência poderemos ter a vontade de poder pensar em ajudar um idoso a desenvolver determinadas capacidades para que possa responder mais eficazmente aos desafios que a vida lhe coloca? Constitui-se, de fato, o conceito de resiliência como um conceito a aprofundar para ajudar a encontrar resposta para algumas das grandes questões e desafios atuais? Será possivel ajudar um educador a formar seres humanos mais resilientes?

Estamos a falar de uma capacidade de resistência inesperada a eventos potencialmente desfavoráveis, que se manifestam contra o que seria previsível, dada as circunstâncias em que os sujeitos foram no passado ou estão no presente envolvido e que possibilitam não só que sejam neutralizadas as consequências negativas que normalmente daí resultam, mas conseguir inclusivamente que possam vir a tornar-se num fator de desenvolvimento humano (Grotberg, 1995), apresentando-se o

Educação \& Realidade, Porto Alegre, v. 40, n. 1, p. 33-51, jan./mar. 2015.

Disponível em: <http://www.ufrgs.br/edu_realidade> 
Envelhecimento e Educação para Resiliência no Idoso

domínio das relações como uma das áreas privilegiadas para identificar os fatores que determinam essa capacidade.

A personalidade do sujeito pode já conter as ferramentas da resiliência. A investigação aponta para que a resiliência é o resultado de características particulares associadas ao comportamento sociável, ao temperamento, caráter e inteligência (Grotberg, 1995). Falamos de características psicológicas do sujeito ao nível da dimensão pessoal e interpessoal na relação. Uma criança, um jovem, um adulto resiliente, implica, portanto, a presença, a procura e o aumento gradual das competências de confronto face à adversidade, socorrendo-se de todos os recursos pessoais: biológicos, psicológicos, e contextuais.

Em forma de síntese, e tendo por pano de fundo o estado da arte sobre resiliência, tomando o número especial (2006) da Annals of the New York Academy of Sciences, dedicado à temática em apreço (Barry M. Lester, Ann Masten, Bruce McEwen Wiley, entre outros), poderemos extrair as seguintes ilações sobre a definição comumente encontrada para esta capacidade humana: resiliência sinônimo de sucesso face ao risco; resiliência como capacidade de resolver problemas; resiliência como capacidade para mudar e/ou se adaptar a circunstâncias difíceis; resiliência como capacidade de ser impermeável ao risco; resiliência algo muito, muito forte.

\section{Conceitos Associados com a Resiliência}

Muitos trabalhos têm sido desenvolvidos focalizando, entre outras, a adaptação positiva ou com sucesso dos indivíduos (Masten, 1994; 1999). De fato, nas sociedades ditas desenvolvidas, a lista das tarefas de desenvolvimento das crianças inclui a adaptação escolar com comportamentos adequados, o aproveitamento acadêmico, a aceitação dos pares, e uma conduta moral de acordo com as regras de organização social da família, da escola, da comunidade e da sociedade em geral. $\mathrm{Na}$ adolescência são solicitadas outras tarefas desenvolvimentais que se prendem com a adaptação às transformações da adolescência, com as relações amorosas e com uma identidade coerente. Na vida adulta as tarefas de desenvolvimento incluem aspetos como a subsistência econômica, o estabelecimento de família, e o desempenho de papeis aceitados pela sociedade.

Segundo Garmezy (1991; 1996) a competência é algo extremamente importante para os programas que promovem a resiliência, como pode ocorrer com um programa de ativação do desenvolvimento humano, concretamente ao nível, por exemplo, de componentes da teoria sociocognitiva (Sousa, 1995; 2006; 2008). Outro que comumente surge associado com resiliência é o conceito de robustez (hardiness). Trata-se de um conceito que tem sido definido como uma característica de personalidade que se expressa por mecanismos cognitivos, sociais e fi- 
siológicos que protegem a saúde e o desempenho, podendo atuar como reforçador da resistência ao stress.

Um outro conceito que, grosso modo, surge associado à resiliência é o conceito de coping. A coping pode corresponder a expressões como forma de lidar com ou estratégias de confronto.

\section{Fatores de Vulnerabilidade}

Vivemos num mundo complexo, repleto de situações portadoras de adversidade e, por conseguinte, potencialmente de risco. Todavia, nem sempre a vulnerabilidade se apresenta como um padrão inevitável para a mesma situação ou para o mesmo indivíduo, o que nos leva a pensar na existência de vários filtros pelas quais a realidade passa, adquirindo significados pessoais diferenciados, em que o aspecto pessoal aparece então como um aspecto crítico, modelado por processos de socialização ocorridos ao longo da vida do ser humano, constituindo aquilo que permite personalizar e contextualizar numa história de vida, o sentido de determinada reatividade (Grotberg, 1999; Rutter, 1999).

Considera-se que estamos perante uma situação de vulnerabilidade quando o sujeito, face ao estressor, não é capaz de mobilizar mecanismos de coping que lhe permitam um desfecho positivo.

Estamos em presença de um fator de risco sempre que as características da pessoa ou do contexto estejam associadas a um aumento da probabilidade de um desenvolvimento desadequado, o que ocorre sempre que as exigências de um desafio ultrapassam a capacidade adaptativa do sujeito, tornando-se a sua reação a esse mesmo desafio disfuncional (Compas; Hinden; Gerhardt, 1995).

Todavia, é de salientar que não existe uma única fonte de vulnerabilidade, uma vez que muitos são os fatores interativos que intervêm neste processo, tornando o efeito do risco indireto.

Ora, o nível de desenvolvimento atingido pelo ser humano é um dos aspectos que influencia a forma como o risco é experienciado, no sentido em que existem diversas vulnerabilidades e vários sistemas protetores em diferentes pontos do desenvolvimento (Masten, 1997).

Para Garmezy $(1991$; 1996) os fatores de risco - que podem ser categorizados (em virtude da vida multifacetada do sujeito) em individuais, interpessoais ou contextuais -, podem ter diversas origens, desde influências genéticas ou biológicas, até situações psicossociais difíceis. Igualmente Rutter (1999) chama a atenção para a necessidade de considerar o stress e os processos de coping a vários níveis, desde o social, ao psicológico e ao neuroquímico, uma vez que cada um destes níveis providenciaria uma perspectiva diferente e complementar, cuja integração seria fundamental para compreender os mecanismos e os processos envolvidos na vulnerabilidade. De fato, estes fatores de risco, por possuírem uma natureza multicausal, refletem-se nos aspectos biológicos,

Educação \& Realidade, Porto Alegre, v. 40, n. 1, p. 33-51, jan./mar. 2015. 45

Disponível em: <http://www.ufrgs.br/edu_realidade> 
psicológicos e sociais (Freitas; Downey, 1998), devendo ser vistos como o resultado de uma interação entre indivíduo-ambiente, assumindo cada uma destas partes um papel ativo.

Mas Emery e Forehand (1996) referem à necessidade de distinguir entre os fatores que moderam o risco e aqueles que o medeiam. No primeiro caso, temos variáveis que são marcadores de uma tendência de aumento ou de diminuição das dificuldades psicológicas. As variáveis mediadoras vão mais longe no sentido de sugerirem mecanismos desenvolvimentais específicos que explicam como o risco se transforma em disfuncionamento.

Por outro lado, a elasticidade e flexibilidade cognitivas inerentes a estes estádios superiores, direcionam o ser humano para uma maior adaptação, aspecto que constitui um conceito fundamental para a compreensão do processo de resiliência, o qual não se relaciona diretamente com mecanismos de resistência ou de dessensibilização.

\section{Fatores Protetores}

O conceito de fator protetor, também conhecido por mediador, surge associado à Psicologia do Desenvolvimento, e rompe com a anterior postura centrada na patologia. Agora ao risco contrapõe-se a proteção e, duma situação de vulnerabilidade pode passar-se a uma situação de desenvolvimento, através duma intervenção planeada onde interage um conjunto de fatores que naquele contexto, naquele indivíduo, e naquele momento, tomam características protetoras que reforçam a capacidade de resistência individual (Sousa, 2009, p. 82).

São quatro os processos distintos que podem originar a rentabilização de um fator de risco em um fator de proteção, a saber: (i) através da redução do impacto do risco, quer por alteração do próprio risco, quer modificando o grau de exposição do indivíduo a esse risco; (ii) pela redução da cadeia de reações negativas que se seguem à exposição aos efeitos nefastos; (iii) pelo aumento da autoestima e da autoeficácia, conseguidas através do contributo das relações interpessoais que o sujeito consegue estabelecer, em estreita ligação com o fato de lhe serem proporcionadas novas experiências e do seu nível de competência no cumprimento de tarefas; e, (iv) pode também ser obtida através da abertura a oportunidades que possibilitem ao sujeito ter acesso a recursos ou a completar importantes transições no seu ciclo de vida.

Vários autores (Brown; D’Emidio-Caston; Benard, 2001; Grotberg, 1999; Vaillant, 1993; Werner; Smith, 2001) categorizam os fatores de proteção em três grandes grupos, designadamente os atributos de personalidade do próprio sujeito, as características da família e as influências do contexto.

A competência social é invocada como um dos fatores que podem ser enquadrados na categoria relativa aos atributos da personalidade 
que favoreceriam os fatores de proteção. Inclui qualidades como flexibilidade, empatia, afeto, responsabilidade e sentido de humor, ou seja, a capacidade para rir de si mesmo e das situações (Sousa, 2006; 2008; 2009; 2010).

Por outro lado e situando-nos na velhice, podemos referir múltiplos fatores associados ao idoso que do nosso ponto de vista podem contribuir para o desempenho de uma vida participativa bem sucedida em todos os contextos relacionais. É o caso das relações sociais que se podem apresentar como promotoras: (i) do estabelecimento de elos afetivos mais firmes que permitem o aumento e estabilização das necessidades básicas de segurança dos idosos; (ii) da integração social dos idosos, favorecendo o seu reconhecimento, valor e competências; (iii) de trocas sociais (dar e receber), conselhos e informações orientadoras e, por último, (iv) da prestação de cuidados a outros, perspectivando o desenvolvimento de sentimentos de utilidade. Também aquele apoio disponibilizado por grupos ou pessoas significativas, como familiares, amigos ou vizinhos ao idoso, em determinadas situações da sua vida quando necessita de assistência e não só, suscitando níveis de satisfação elevados, se apresenta como fator protetor. Estamos a falar do papel protetor das forças sociais e a sua influência no bem-estar subjetivo e/ou psicológico bem como na promoção da adaptação dos idosos, quando estes são confrontados com situações normativas, fomentando a saúde independentemente do nível de stresse, traduzindo-se na premissa de quanto maior for o apoio social, menor será o mal-estar psicológico experimentado e, por outro lado, quanto menor for o apoio social, maior poderá será a incidência dos transtornos psicopatológicos. Em modo contrário, alguns fatores acarretam desvantagens sendo considerados de risco, por exemplo, solidão, insatisfação com familiares próximos, necessidades especiais.

Contudo, convém sublinhar que nenhum fator protetor é por si garante de uma vida participativa vivida com sucesso nem um fator de risco é necessariamente determinante no desenvolvimento.

\section{Considerações Finais e Contributos}

Afirmamos no decurso deste artigo que a resiliência se prende com a possibilidade de desenvolver capacidades necessárias para se sobrepor às adversidades quotidianas, superando-as e transformando-se, com diferentes níveis de construção de uma vida pessoal e profissional significativa, saudável e construtiva. E que podemos pensá-la como uma noção que pretende consubstanciar conceptualmente uma especificidade estrutural do desenvolvimento humano, que se traduz na capacidade que denotam certas pessoas, grupos ou comunidades para fazer face ou mesmo ultrapassar os efeitos desestruturantes que seriam muito prováveis em consequência da exposição a certas experiências.

Educação \& Realidade, Porto Alegre, v. 40, n. 1, p. 33-51, jan./mar. 2015.

Disponível em: <http://www.ufrgs.br/edu_realidade> 
Neste momento, um aspecto interessante, a que gostaríamos de sublinhar, prende-se com as investigações por nós orientadas, em termos de cursos de mestrado, doutoramento e pós-doutoramento, quer de universidades portuguesas (Universidade do Algarve, Universidade de Aveiro, entre outras), quer de universidades espanholas (Universidade de Huelva, Universidade de Málaga, Universidade de Granada, Universidade de Sevilha e Universidade de Barcelona), quer de universidade brasileira (Universidade Federal do Rio Grande do Sul) a conclusões a que os nossos orientandos fazem comumente referência e que apontam um fator frequentemente encontrado neste tipo de população, objeto de estudo: o fator - locus de controlo interno, entendido como a convicção que o idoso tem de conseguir controlar a sua vida, atribuindo a si próprio os êxitos e os fracassos do seu quotidiano. Por seu turno, esta noção de controlo sobre o que o rodeia, interfere na percepção que o mesmo faz acerca de si próprio. O que poderá explicar a presença, nas investigações que identificam idosos resilientes, de valores elevados em variáveis como a autoeficácia, a autoconfiança, a autoestima e a capacidade de autoavaliação.

Outra característica referenciada nas investigações por nós conduzidas como orientadora sobre seres humanos resilientes prende-se com a propensão que o idoso apresenta no sentido de manter expectativas elevadas quanto ao próprio futuro, bem como o estabelecimento claro de objetivos a atingir.

Acresce, ainda, que essas mesmas investigações indiciam que diversos contextos como o familiar e o educativo podem ser identificados como um lugar de ativação da resiliência do idoso. De fato, as famílias podem influenciar a resiliência dos seus idosos demonstrando elas próprias características em termos de resiliência. Os fatores de origem familiar, sendo de enorme importância na construção que o sujeito faz acerca de si próprio, influenciam e entrelaçam-se com fatores individuais, como sejam a autoeficácia, a autoestima, o autoconceito, autorrealização, determinando os processos e os mecanismos por que se rege a resiliência. Mas é óbvio que este suporte social não só tem que estar presente, mas tem que ser internalizado pelo sujeito, o que significa que ser resiliente passa também pela capacidade de cada indivíduo saber reconhecer, dentro da matriz interpessoal em que se move, quem o ama e quem estabelece com ele ligações saudáveis e de confiança.

Recebido em 11 de março de 2014 Aprovado em 04 de setembro de 2014

\section{Referências}

BALTES, Paul. On the Incomplete Architecture of human Ontogeny: selection, optimization, and compensation as foundation of developmental theory. American Psychologist, v. 52, n. 4, p. 366-380, 1997. 
BALTES, Paul. Theoretical Propositions of Life-Span Development Psychology: on the dynamics between growth and decline. Development Psychology, v. 23, n. 5, p. 611-626, 1987.

BALTES, Paul; BALTES, Margret (Org.). Successful Aging: perspetives from the behavioral sciences. New York: Cambridge University Press, 1990.

BRONFENBRENNER, Urie. The Ecology of Human Development: experiments by nature and design. Cambridge, MA: Harvard University Press, 1979.

BROWN, Joel; D’EMIDIO-CASTON, Marianne; BENARD, Bonnie. Resilience Education. Thousand Oaks, CA: Corwin Press, 2001.

COMPAS, Bruce; HINDEN, Beth; GERHARDT, Cynthia. Adolescent Development and Process of Risk Resilience. Annual Review of Psychology, v. 46, p. 265293, 1995.

EMERY, Robert; FOREHAND, Rex. Parental Divorce and Children's Well-being: a focus on resilience. In: HAGGERTY, Robert; SHERROD, Lonnie; GARMEZY, Norman; RUTTER, Michael (Org.). Stress, Risk, and Resilience in Children and Adolescents. Cambridge, England: Cambridge University Press, 1996. P. 64-99.

FERNÁNDEZ-BALLESTEROS, Rocío. Vivir con Vitalidad. Madrid: Ediciones Pirámide, 2002.

FONSECA, António. Desenvolvimento Humano e Envelhecimento. Lisboa: Climepsi Editores, 2005.

FREITAS, Antonio; DOWNEY, Geraldine. Resilience: A Dynamic Perspetive. International Journal of Behavioral Development, v. 22, n. 2, p. 263-285, 1998.

FREITAS, Elizabete; PY, Ligia; NERI, Anita; CANÇADO, Flávio; DOLL, Johannes; GORZONI, Milton. Tratado de Geriatria e Gerontologia. Rio de Janeiro: Guanabara Koogan, 2006.

FREUND, Alexandra; BALTES, Paul. Selection, Optimization, and Compensation as Strategies of Life Management: correlations with subjetive indicators of successful aging. Psychology and Aging, v. 13, n. 4, p. 531-543, 1998.

FRIED, Linda; FREEDMAN, Marc; ENDRES, Thomas; WASIK, Barbara. Building Communities that Promote Successful Aging. Western Journal of Medicine, v. 167, n. 2, p. 216-219, 1997.

GARMEZY, Norman. Reflections and Commentary on Risk, Resilience, and Development. In: HAGGERTY, Robert; SHERROD, Lonnie; GARMEZY, Norman; RUTTER, Michael (Org.). Stress, Risk, and Resilience in Children and Adolescents. Cambridge, England: Cambridge University Press, 1996. P. 1-18.

GARMEZY, Norman. Resiliency and Vulnerability to Adverse Developmental Outcomes Associated with Poverty. American Behavioral Scientist, v. 34, n. 4, p. 416-430, 1991.

GROTBERG, Edith. A Guide to Promoting Resilience in Children: strengthening the human spirit. The Hague: Bernard Van Leer Foundation, 1995.

GROTBERG, Edith. Tapping your Inner Strength. How to Find Resilience to Deal with Anything. Oakland, CA: New Harbinger Publications, 1999.

GROTBERG, Edith. The International Resilience Project: findings from the research and the effectiveness of interventions. 1997. Disponível em: <http://files. eric.ed.gov/fulltext/ED419584.pdf>. Acesso em: 14 jan. 2012.

INE. Instituto Nacional de Estatística - Censos de 2011. 2011. Disponível em: $<$ http://censos.ine.pt/xportal/xmain?xpid=CENSOS\&xpgid=censos2011_apresentacao>. Acesso em: 8 mar. 2013. 
LASUÍTA, Adele. A life-span framework for adult vocational behavior. Guidance and Counselling, v. 4, n. 5, p. 15-25, 1989.

LÓPEZ, Miguel. La Integración escolar, otra Cultura. Málaga: Junta de Andalucía, Consejería de Educación y Ciencia, 1990.

LUPIEN, Sonia; WAN, Nathalie. Successful Aging: from cell to self. Philosophical Transactions of the Royal Society, v. 359, p. 1413-1426, 2004.

MANCIAUX, Michel (Org.). La Resiliencia: resistir y rehacerse. Barcelona: Gedisa, 2003

MASTEN, Ann. Resilience in Children at Risk. Research/Practice, v. 5, p. 4-8, 1997.

MASTEN, Ann. Resilience in Individual Development: successful adaptation despiste a risk and adversity. In: WANG, Margaret; GORDON, Edmund (Org.). Educational Resilience in Inner-City America: challenges and prospects. Hidlsdale, New Jersey: Lawrence Erlbaum Associates, 1994. P. 3-35.

MASTEN, Ann. The Promise and Perils of Resilience Research as a Guide to Preventive Interventions: comments on rolf and johnson. In: GLANTZ, Meyer; JOHNSON, Jeannette (Org.). Resilience and Development: positive life adaptations. New york: Plenum, 1999. P. 251-257.

OHIO STATE UNIVERSITY. Fostering Resilience in Children. Bulletin 875-99, 2002. Disponível em: <http://ohioline.osu.edu/b8875_2.html>. Acesso em: 20 de jun. 2012

ORGANIZAÇÃO MUNDIAL DA SAÚDE (OMS). Envelhecimento Ativo: uma política de saúde. Brasília: Organização Pan-Americana de Saúde, 2005.

PAÚL, Constança; FONSECA, António. Psicossociologia da Saúde. Lisboa: Climepsi Editores, 2001.

PAÚL, Constança; FONSECA, António. Envelhecer em Portugal. Lisboa: Climepsi Editores, 2005.

PHELAN, Elizabeth; LARSON, Eric. "Successful aging"--Where next? Journal of the American Geriatrics Society, v. 50, n. 7, p. 1306-1308, 2002.

PORDATA - Base de Dados Portugal Contemporâneo. INE - Estimativas Anuais da População Residente, 2012.

RAMOS, Emílio (Org.). Apuntes sobre Educación de Personas Adultas y Acción Comunitária. Valencia: Diálogos, 2003.

ROWE, John; KAHN, Robert. Successful Aging. The Gerontologist, v. 37, n. 4, p. 433-440, 1997.

RUTTER, Michael. Psychosocial Adversity and Child Psychopathology. The British Journal of Psychiatry, v. 174, p. 480-493, 1999.

SOUSA, Carolina. Ativação do Desenvolvimento Cognitivo e Facilitação da Aprendizagem, In: TAVARES, Bonboir et al. Ativação do Desenvolvimento Psicológico nos Sistemas de Formação. Aveiro: Edições CIDInE, 1995. P. 279-296.

SOUSA, Carolina. Características Psicológicas de la Persona Adulta. In: RAMOS, Emílio (Org.). Apuntes sobre Educación de Personas Adultas y Acción Comunitária. Valencia: Diálogos, 2003. P. 79-96.

SOUSA, Carolina. Competência Educativa: o papel da educação para a resiliência. Revista Educação Especial, n. 31, p. 9-24, 2008.

SOUSA, Carolina. Educação para a Resiliência. Tavira: Município de Tavira 2006.

50 Educação \& Realidade, Porto Alegre, v. 40, n. 1, p. 33-51, jan./mar. 2015 Disponível em: <http://www.ufrgs.br/edu_realidade> 
SOUSA, Carolina. Motivação e Resiliência em Contextos Educativos. In: DOS SANTOS, Bettina; BOZA, Ángel (Org.). A Motivação em Diferentes Cenários. Brasil, Porto Alegre: EDIPUCRS, 2010. P. 151-172.

SOUSA, Carolina. Resiliência na Educação Superior. In: ISAIA, Silvia; BOLZAN, Doris (Org.). Pedagogia Universitária e Desenvolvimento Profissional Docente. Porto Alegre: EDIPUCRS, 2009. P. 65-100.

TEIXEIRA, Ilka; NERI, Anita. Envelhecimento Bem-Sucedido: uma meta no curso de vida. Psicologia USP, v. 19, n. 1, p. 81-94, 2008.

UNITED NATIONS. World Population Ageing: 1950-2050. New York: UN Population Division, Department of Economic and Social Affairs, 2001.

VAILLANT, George. The Wisdom of the Ego. Cambridge, Harvard University Press, 1993.

WERNER, Emmy; SMITH, Ruth. Journeys from Childwood to Midlife: risk, resilience and recovery. London: Cornell University Press, 2001.

Carolina Silva Sousa é doutora em psicologia da educação pela Universidade do Minho, PT (1993) com estágio de doutoramento em Paris, Laboratório de Psicologia Diferencial, Universidade René Descartes (Paris V) - Sorbonne (1991). É a coordenadora da sede, em Portugal, do Coletivo Docente Internacional INNOVAGOGÍA e Investigadora no Centro de Investigação em Educação e Psicologia da Universidade de Évora, Portugal (CIEP).

E-mail: carolinasousa639@gmail.com

Francisco P. Rodríguez-Miranda é professor Ajudante Doutor da Universidade de Extremadura (Espanha). Investigador no Centro de Investigação em Didáticas Específicas e Investigação na Aula da Universidade de Huelva / Equipa de Investigação GAIA (HUM133). Ex-secretário do Mestrado Oficial de Educação Especial da Universidade de Huelva. Tem feito várias estadias de pesquisa em universidades de Portugal, entre elas Lisboa e Algarve. E-mail: fdepaularomi@unex.es 